\title{
Algumas notas sobre 0 ensino de Paleografia no Brasil
}

\author{
Leonardo Lennertz Marcotulio* \\ Vanessa Martins do Monte**
}

Artículo recibido:

16 de junio de 2020

Artículo aceptado:

5 de octubre de 2020

Artículo de revisión

\section{Resumo}

Neste texto, apresentamos algumas notas para a construção de um panorama do ensino de Paleografia no Brasil - tema bastante pouco explorado em textos científicos nacionais - em nível de graduação, pós-graduação e cursos livres, conhecidos comumente como oficinas de Paleografia. Além disso, dada a ausência de bibliografia específica sobre o ensino de Paleografia em português, também é nosso objetivo ampliar a divulgação de métodos estrangeiros, que pouco circulam no Brasil. Por fim, a partir de um diagnóstico realizado com base em uma amostra de oficinas presenciais de Paleografia, elaboramos uma proposta sobre estratégias de leitura de textos manuscritos.

* Universidade Federal do Rio de Janeiro, Brasil

* Universidade de São Paulo, Brasil

marcotulio@letras.ufrj.br vmmonte@usp.br INVESTIGACIÓN BIBLIOTECOLÓGICA, vol. 35, núm. 87, abril/junio, 2021, México, ISSN: 2448-8321 pp. 57-84 
Palavras-chave: Ensino de Paleografia; Método em Paleografia de Leitura; Estratégias de Leitura de Textos Manuscritos

\author{
Some notes on the teaching of Paleography in Brazil \\ Leonardo Lennertz Marcotulio and Vanessa Martins do Monte
}

\begin{abstract}
This article presents some notes on the construction of a panorama regarding the teaching of Paleography in Brazil - a topic that has been poorly explored in national scientific texts - at graduate and undergraduate levels and free courses, commonly known as Paleography workshops. In addition, given the absence of specific bibliography in the teaching of paleography in Portuguese, it will also be our goal to expand the dissemination of foreign methods which do not circulate in Brazil. Finally, based on a diagnosis made with a sample of Paleography workshops, we elaborated a proposal on strategies for reading handwritten texts appearing eventually in some texts.
\end{abstract}

Keywords: Teaching Paleography; Reading Paleography Method; Strategies for Reading Handwritten Texts

\title{
Algunas notas sobre la enseñanza de Paleografía en Brasil Leonardo Lennertz Marcotulio y Vanessa Martins do Monte
}

\section{Resumen}

En este texto presentamos algunas notas para la construcción de un panorama de la enseñanza de Paleografía en Brasil - tema muy poco tratado en textos científicos nacionales - tanto a nivel de grado y posgrado como en cursos libres, conocidos comúnmente como talleres de Paleografía. Además, debido a la ausencia de bibliografía específica sobre la enseñanza de Paleografía en portugués, nuestro objetivo será también fomentar la divulgación de métodos extranjeros, de poca circulación en Brasil. Finalmente, a partir de un análisis de talleres presenciales de Paleografía, elaboramos una propuesta sobre metodologías de lectura de textos manuscritos.

Palabras clave: Enseñanza de Paleografía; Mé- 


\section{INTRODUÇÃO}

interesse pela Paleografia vem crescendo de forma significativa nos últimos tempos, o que se traduz diretamente pelo aumento da demanda de seu ensino dentro e fora das universidades. Com o intuito de observar a dimensão que o ensino de Paleografia de fato pode ter, é de grande utilidade a consulta aos mapeamentos já realizados.

Para o conhecimento do que tem sido praticado na Espanha, contamos com os levantamentos periódicos realizados pela Sociedad Española de Ciencias y Técnicas Historiográficas sobre as disciplinas de Paleografia, Diplomática, Epigrafia e Numismática oferecidas nas universidades públicas espanholas. A partir da leitura dos exemplares de 2014 e 2016 do Catálogo de asignaturas del área de Ciencias y Técnicas Historiográficas en la universidad española (Santiago Fernández e López Villalba, 2014; Santiago Fernández, 2016), é possível observar que a Paleografia, compartilhando ou não espaço com a Diplomática, costuma ser oferecida, como disciplina obrigatória ou optativa, nos cursos de graduação em História, História da Arte, História e Ciências da Música, Arqueologia, Informação e Documentação, Humanidades e Patrimônio, Filologia Espanhola e Estudos Clássicos. Consta, também, como disciplina optativa em diversos cursos de mestrado das áreas de História e Arquivologia. Além disso, embora não esteja presente no título da disciplina, percebe-se que a Paleografia faz parte do conteúdo de outras disciplinas, como História da escritura, Cultura escrita, O documento e o livro, História do documento, Leitura do documento histórico, Leitura de textos antigos e medievais, Análise histórica da escritura e dos documentos, $\mathrm{O}$ patrimônio escrito, etc.

Para o caso de Portugal, António Cruz (1966) faz, em Observações sobre o estudo da paleografia em Portugal, um cuidadoso e extenso relato sobre o ensino de Paleografia em universidades portuguesas desde a criação dos primeiros centros de estudo até a década de sessenta. Para um retrato mais atual, dispomos da contribuição de Maria José Azevedo Santos, publicada em 2000, ainda que a atenção esteja focada nas disciplinas de Paleografia e Diplomática oferecidas somente pelos cursos da Faculdade de Letras da Universidade de Coimbra. A Universidade conta com o Instituto de Paleografia e Diplomática, responsável pela oferta de disciplinas, obrigatórias ou optativas, para os cursos de graduação em História, de especialização em Ciências Documentais e de mestrado em História da Idade Média ou em Ciências Musicais.

Embora se tenha notícias sobre o ensino de Paleografia em diversas cidades do Brasil, não contamos ainda com um mapeamento oficial e atualizado. O último de que se tem notícia foi o levantamento feito por Cárcel Ortí 
(1996), a partir de Guias do Estudante publicados até 1995, voltado ao ensino de Paleografia e Diplomática em universidades europeias, americanas e asiáticas, com especial destaque às universidades espanholas. Até essa data, no Brasil, o ensino de Paleografia acontecia, de forma regular, na graduação, mais especificamente no curso de Bacharelado em Arquivologia na Universidade de Brasília ${ }^{1}$ e na Universidade Federal de Santa Maria. ${ }^{2}$ Já na pós-graduação (lato sensu), a Paleografia marcava presença em cursos de Especialização em Arquivos / Arquivologia, oferecidos pela Universidade Federal da Bahia $^{3}$ e pela Universidade de São Paulo. ${ }^{4}$

Nesse sentido, de modo a contribuir à construção de um panorama nacional e mais atualizado, o nosso primeiro objetivo, neste artigo, é trazer algumas informações relativas a atividades de ensino de Paleografia no Brasil, mais particularmente nos estados de São Paulo e Rio de Janeiro, durante o ano de 2019. O recorte geográfico se justifica por uma simples questão de proveniência de seus autores. O cenário descrito a partir dessas duas regiões não é, no entanto, revelador do comportamento de todo o país. Ainda por ser realizado, um panorama nacional demandaria uma pesquisa bastante ampla e minuciosa, a ser feita de modo colaborativo por diversos colegas que atuam na área - o que revelará a atuação ativa de outros centros, como Bahia, Minas Gerais, Brasília e Rio Grande do Sul, somente para citar alguns exemplos. Além disso, a publicação de um panorama como esses requer uma extensão de texto bem maior do que a de um artigo científico.

1 "La Universidade de Brasilia ofrece un "Curso de Graduação em Arquivologia" (creado en 1991), de 5 años de duración (2.160 h.), en donde se cursan, entre otras materias, "Tipos y formas de los documentos de archivo (incluyendo Paleografía y Diplomática)” (150 h.), "Teoría archivística e historia de los archivos" (90 h.), y "Leer y comprender los documentos de archivo" (120 h.). El diploma concedido es es de "Bacharel em Arquivologia”." (Cárcel Ortí, 1996: 107).

2 "La Faculdade de Arquivologia-UFSM ofrece una "Habilitação em Arquivos Empresariais / Habilitação em arquivos medicos” (fundado en 1977), de 4 años de duración (3.030 h.), donde se puede cursar "Tipos y formas de los documentos de archivo (incluyendo Paleografía y Diplomática)" (150 h.), "Teoría archivística e historia de los archivos" (150 h.), "Leer y comprender los documentos de archivo" (80h). El diploma concedido es el de "Bacharel em Arquivologia”." (Cárcel Ortí, 1996: 108).

3 "La Escola de Biblioteconomia e Documentação, Curso de Pos-Graduação em Arquivologia de la Universidade Federal da Babia / Ministerio da Educação imparte desde 1988 el título de "Curso de Pos-Graduação em Arquivologia”, de 1 año de duración (615 h.), entre cuyas materias se encuentran las "Ciencias auxiliares (Paleografía, Diplomática...)", "Archivística" y "Doctrina e historia de los archivos", y como trabajo práctico: "Leer y comprender los documentos de archivo”. El diploma concedido es el de "Especialización en Archivística”." (Cárcel Ortí, 1996: 107).

4 "El Instituto de Estudios Brasileiros. Escola de Comunicações de la Universidade de São Paulo ofrece un "Curso Anual de Especialização em Organização de Arquivos (fundado en 1986), de 3 a 4 meses de duración (500 h.), donde se puede cursar "Tipos y formas de los documentos de archivo (incluyendo Paleografía y Diplomática)" (32 h.), "Teoría archivística e historia de los archivos" (24 h.) y entre los trabajos práticos "Leer y comprender los documentos de archivo" (20 h.). El diploma concedido es el de "Especialização em Arquivos”." (Cárcel Ortí, 1996: 108). 
Ademais de informações relativas ao ensino de Paleografia em cursos de graduação e pós-graduação, como comumente se encontram nos mapeamentos já apresentados, queremos também expandir o olhar para além dos muros da universidade, posicionando o foco nos cursos livres, também conhecidos como oficinas de Paleografia.

Além do levantamento das oficinas oferecidas no ano de 2019, trazemos também alguns questionamentos e reflexões sobre o ensino em si: como se dá o ensino de Paleografia nas oficinas?; como se ensina a ler um texto antigo? A partir de um diagnóstico realizado em uma pequena amostra de oficinas na modalidade presencial, ${ }^{5}$ refletimos sobre o ensino de Paleografia, com especial destaque ao método e às estratégias empregadas para o ensino de leitura dos textos manuscritos. Como contribuição, diante de um conjunto heterogêneo de textos da documentação remanescente, englobando tanto os de leitura imediata quanto os de difícil leitura, elaboramos um procedimento sequencial de estratégias de leitura, apoiado em níveis de natureza diversa, como filológico-paleográfico e linguístico-lexical.

\section{ELEMENTOS PARA A CONSTRUÇÃO DE UM PANORAMA BRASILEIRO: MAPEAMENTO do ensino de Paleografia em São Paulo e no Rio de Janeiro}

Apresentamos, nesta seção, um breve mapeamento do ensino de Paleografia em cursos de graduação e pós-graduação de universidades de São Paulo e Rio de Janeiro. Para esse levantamento, contamos com a nossa própria experiência como docentes da Universidade de São Paulo e da Universidade Federal do Rio de Janeiro, com informações extraídas de comunicação com os pares de nossos círculos de atuação, assim como com documentos oficiais, tais como grades curriculares ou fluxogramas, disponibilizados em linha.

Diferentemente da realidade das universidades espanholas e portuguesas, em que a Paleografia costuma marcar presença mais constante em cursos de graduação em História, em São Paulo e no Rio de Janeiro a Paleografia pode ser mais facilmente encontrada em cursos das Ciências da Informação.

O curso de graduação em Arquivologia da Unesp-Marília, ${ }^{6}$ único do estado de São Paulo, mantém Paleografia como uma disciplina obrigatória logo no $2^{\circ}$ período do curso. A Prof. ${ }^{a}$ Dr. ${ }^{a}$ Sonia Troitiño Rodriguez é a docente responsável pela disciplina.

5 Sobre o ensino de Paleografia em cursos e oficinas online, consultar Zozaya (2014) e Borges e Silva (2018).

6 https://www.marilia.unesp.br/\#!/graduacao/cursos/arquivologia/grade-curricular/estrutura-curricular-2019 Consulta em 20 jan 2020. 
No Rio de Janeiro há dois cursos de graduação em Arquivologia. No curso da Universidade Federal do Estado do Rio de Janeiro (UNIRIO), Paleografia consta da grade curricular, mas no rol de disciplinas optativas, ${ }^{7}$ sendo oferecida anualmente pelo Prof. Dr. Franklin Leal ou pelo Prof. Ms. Marcelo Siqueira.

$\mathrm{Na}$ Universidade Federal Fluminense, ${ }^{8}$ no entanto, a disciplina Paleografia não aparece no conjunto das disciplinas regulares do curso de Arquivologia, podendo ser oferecida somente na disciplina genérica de nome "Optativa". Nessa universidade, como disciplina optativa, Paleografia também é oferecida em cursos de bacharelado ou licenciatura em História. Em 2019, por exemplo, foi oferecida a disciplina "História e Paleografia", ministrada pelo Prof. Dr. Mário Bastos, para alunos dos cursos de História e Antropologia.?

$\mathrm{Na}$ contramão do fluxo descontínuo e decrescente seguido pelos cursos de História e Arquivologia, nos cursos de Letras, não mapeados por Cárcel Ortí (1996), o ensino de Paleografia tem ganhado força desde a última década. No entanto, não há, via de regra, uma disciplina obrigatória regularmente oferecida que faça parte do currículo formal.

$\mathrm{O}$ aumento do interesse acadêmico da área de Letras e Linguística pela Paleografia se deve a algumas razões. Dentre elas, pode-se citar o amplo número de projetos locais, regionais e nacionais sobre a história da língua. Investigações de cunho histórico demandam o levantamento de fontes primárias e seu tratamento fidedigno, seguindo rigorosos preceitos filológicos que culminam na publicação de edições conservadoras, daí a exigência de uma formação paleográfica consistente.

Além disso, outro fator que impulsionou o interesse recente pela $\mathrm{Pa}$ leografia, não apenas restrito à área de Letras e Linguística, é a quantidade crescente de acervos digitais. A digitalização de documentos tem sido um processo contínuo e bastante incentivado em diversas instituições brasileiras de salvaguarda de patrimônio material. Com a facilidade de acesso aos documentos, antes restritos à consulta física in loco, aumenta-se a procura por métodos seguros de decifração e leitura de documentos. A Paleografia é per si a área que se dedica a esses processos.

Ao menos em sua dimensão prática de disciplina auxiliar para a leitura de documentos, observa-se um deslocamento da Paleografia: de parte integrante das Ciências Históricas passa também a peça fundamental para o

7 http://www.unirio.br/arquivologia/arquivos/Fluxograma_Arquivologia\%202013\%20-\%20 atual\%2009-02-17.pdf Consulta em 20 jan 2020.

8 http://iacs.sites.uff.br/wp-content/uploads/sites/226/delightful-downloads/2018/04/Arquivologia_Grade-2018_REV01.pdf Consulta em 20 jan 2020. 
entendimento da história da língua. As iniciativas que propõem um diálogo mais estreito entre Paleografia e Filologia são mais antigas na Linguística Hispânica. Já é possível observar, desde as últimas décadas do século passado, resultados advindos de grandes projetos, como os inúmeros volumes de Textos para la historia del español, organizados incialmente, desde 1991, pelo Professor Pedro Sánchez Prieto-Borja, da Universidad de Alcalá de Henares; em terras americanas, merecem destaque os trabalhos desenvolvidos pela professora Concepción Company Company, da Universidad Nacional Autónoma de México, iniciados pelos Documentos lingüísticos de la Nueva España - Altiplano Central, obra publicada em 1994.

Desde então, o interesse em estudos de linguística histórica a partir de fontes documentais cresce vertiginosamente. Novos grupos de investigação e projetos de corpora extraídos de acervos locais começam a aparecer, culminando na elaboração de projetos maiores, como a Red Internacional Charta (http://www.redcharta.es), idealizadora do Corpus Hispánico y Americano en la Red. Textos Antiguos (CHARTA) (http://www.charta.es/), coordenado atualmente pela professora Belén Almeida (Universidad de Alcalá de Henares), e a rede latino-americana responsável pela criação do Corpus Diacrónico y Diatópico del Español de América - CORDIAM (http://www.cordiam.org/), coordenado pelas professoras Concepción Company Company (Universidad Nacional Autónoma de México) e Virginia Bertolotti (Universidad de la República, Uruguay), somente para citar alguns exemplos.

A Linguística Portuguesa acompanha esse movimento. O estudo da língua portuguesa no período medieval, de longa tradição em Portugal, se viu favorecido pela criação do Corpus Informatizado do Português Medieval (https://cipm.fcsh.unl.pt/), um projeto de pesquisadores e professores do Centro de Linguística da Universidade Nova de Lisboa, coordenado inicialmente pela professora Maria Francisca Xavier. No Brasil, equipes regionais têm somado esforços para a execução do projeto nacional Para a História do Português Brasileiro (https://sites.google.com/site/corporaphpb/), coordenado originalmente pelo professor Ataliba de Castilho, da Universidade de São Paulo, e desde 2019 pelo professor Sandro Marengo, da Universidade Federal de Sergipe.

Na Universidade de São Paulo (USP), não há uma disciplina obrigatória ou optativa dedicada exclusivamente à Paleografia na graduação, nem no curso de Letras nem no curso de História. Sabemos, contudo, que algumas disciplinas tratam de Paleografia, como é o caso da disciplina Filologia Portuguesa, obrigatória para o curso de Letras. A ementa da disciplina prevê em seu programa a discussão do conceito e do objeto da Filologia e de suas "relações 
com a Diplomática, com a Codicologia e com a Paleografia". ${ }^{10}$ Dependendo da abordagem do docente, é possível que a Paleografia esteja presente em boa parte do curso, principalmente quando se prevê um trabalho final de edição e estudo de documentos manuscritos.

Há também uma disciplina optativa de graduação, aberta a discentes de outros cursos, intitulada Filologia Portuguesa: edição de documentos brasileiros. A disciplina vem sendo ministrada regularmente desde 2017 no Instituto de Estudos Brasileiros (IEB) da USP, pela Prof ${ }^{a}$. Dr ${ }^{a}$. Vanessa Monte e pelos Profs. Drs. Sílvio Toledo Neto e Phablo Fachin. O curso conta com abordagens teóricas sobre Paleografia e com aulas práticas de decifração e leitura dos manuscritos pertencentes ao Arquivo do IEB, com destaque para a coleção Alberto Lamego. Tendo em vista o manuseio de documentos, na maioria dos casos testemunhos únicos, o número máximo de discentes é restrito: cada turma comporta até 15 alunos. Frequentemente recebem-se alunos do curso de História, que lidam com fontes primárias e buscam métodos científicos de leitura e transcrição. Além da evidente afinidade temática com o Arquivo, o fato de a disciplina ser ministrada no IEB guarda uma relação histórica com o Instituto. Foi lá que de 1996 a 2007 a Prof ${ }^{a}$. Dr ${ }^{a}$. Yedda Dias Lima ministrou a disciplina optativa Paleografia $I .{ }^{11} \mathrm{O}$ estreitamento das relações entre o NEHiLP (Núcleo de Apoio à Pesquisa em Etimologia e História da Língua Portuguesa, http://nehilp.prp.usp.br), por meio do grupo de pesquisas ETeP (Edição de Textos em Português, http://etep.fflch.usp.br), com o Arquivo do IEB permitiu a continuidade da tradição do ensino de $\mathrm{Pa}$ leografia no interior daquele Instituto. ${ }^{12}$

Pesquisando-se o rol de disciplinas já ministradas, encontra-se no Programa de Pós-Graduação em Filologia e Língua Portuguesa da USP uma disciplina específica de Paleografia e de Codicologia, ligada à linha de pesquisa Filologia Portuguesa, intitulada Paleografia e Codicologia: Fundamentos, Reflexões e Práticas. A disciplina foi criada recentemente pelo Prof. Dr. Sílvio Toledo Neto e sua primeira turma foi ministrada no primeiro semestre de 2019. Além disso, no Programa de Pós-Graduação em História Social, há duas disciplinas

10 https://uspdigital.usp.br/jupiterweb/obterDisciplina?nomdis $=\&$ sgldis $=$ flc0284 Consulta em $20 \mathrm{fev} 2020$.

11 https://uspdigital.usp.br/jupiterweb/obterDisciplina?sgldis=IEB0101\&verdis=1 Consulta em 01 mar 2020.

12 Devido à ampla demanda pela formação em Paleografia e considerando a limitação de discentes na disciplina optativa, o NEHiLP e o ETeP oferecem uma vez por semestre, desde 2016, uma Oficina de Paleografia, no formato curso de extensão. As oficinas recebem público diverso, composto por graduandos e pós-graduandos da USP, bem como por profissionais de órgãos públicos e privados que lidam com arquivos e documentação manuscrita de modo geral. 
ativas relacionadas à Paleografia: Paleografia e Escritura, ${ }^{13}$ cujos docentes responsáveis são as Prof. ${ }^{a}$ s Dr. ${ }^{a}$ s Ana Maria Camargo (FFLCH-USP) e Sonia Troitiño Rodriguez (Unesp), e Paleografia Templária: Escritura Pragmática e Recurso à Escrita nos Manuscritos da Série $56 \mathrm{H},{ }^{14}$ de responsabilidade dos Profs. Drs. Marcelo Candido da Silva (FFLCH-USP) e Bruno Salles (UFOP).

No curso de Letras da Universidade Federal do Rio de Janeiro (UFRJ), assim como ocorre no curso de Letras da USP, tampouco há uma disciplina obrigatória específica sobre Paleografia. O contato com a área acontece, assim, nas disciplinas Fundamentos de Crítica Textual e Introdução à Crítica Textual, oferecidas pelo Setor de Filologia e ministradas pelas Prof. as Dr. as Karen Alonso e Deise Pinto, e na disciplina História da Língua Portuguesa, do Setor de Língua Portuguesa, oferecida pelos Profs. Drs. Célia Lopes, Afranio Barbosa e Leonardo Marcotulio. Eventualmente, também são ofertadas disciplinas optativas com conteúdos de Crítica Textual e Paleografia por ambos os Setores. ${ }^{15}$ Já no Programa de Pós-Graduação em Letras Vernáculas da UFRJ a Paleografia encontra lugar na disciplina Filologia Portuguesa e Crítica Textual, que vem sendo ministrada pelos Profs. Drs. Dinah Callou e Afranio Barbosa, e, mais recentemente, pelo Prof. Dr. Leonardo Marcotulio.

Ainda que o cenário não seja uniforme (e muito menos animador), é possível destacar alguns pontos positivos em relação ao resultado obtido a partir do levantamento de Cárcel Ortí (1996): (i) a presença da Paleografia para além dos cursos de História e Ciências da Informação, com especial destaque aos cursos de Letras, em que é possível observar, cada vez mais, a necessidade do estudo de Paleografia em constante diálogo com outras disciplinas, como Filologia / Crítica Textual e História da língua portuguesa; (ii) a participação do Rio de Janeiro no ensino formal de Paleografia, antes não contemplada, tanto no nível de graduação quanto pós-graduação; e, por fim, (iii) a presença da Paleografia em cursos de graduação em distintas universidades de São Paulo.

Como se vê nesse breve levantamento, a Paleografia parece resistir no âmbito universitário. Embora o papel desempenhado pelos cursos de Letras

13 A primeira turma da disciplina foi ministrada de 09/10/2018 a 30/10/2018, no prédio de História e Geografia (FFLCH-USP), e a segunda turma, de 19/08/2019 a 08/09/2019, no IEB-USP. https://uspdigital.usp.br/janus/turma/oferecimento/buscaOferecimento.jsf Consulta em 01 mar 2020

14 A disciplina foi ministrada de 10/04/2019 a 16/04/2019 no prédio de História e Geografia (FFLCHUSP). https://uspdigital.usp.br/janus/turma/oferecimento/buscaOferecimento.jsf Consulta em 01 mar 2020.

15 Para suprir a carência de cursos de caráter mais prático especificamente voltados para Paleografia, o abEFil (Laboratório de Estudos Filológicos, https://labefil.letras.ufrj.br), coordenado pelo Prof. Dr. Leonardo Marcotulio, oferece anualmente, como curso de extensão, a Oficina de Paleografia e Edição de Textos (PalETe). 
na promoção da Paleografia represente um agradável e bem-vindo respiro ao campo, a demanda pela área ainda parece ser maior do que a oferta.

Um dos motivos que poderia explicar o cenário de escassa formação especializada na área é a pouca oferta de cursos de Paleografia, tanto em nível de graduação quanto de pós-graduação, aliada à não-obrigatoriedade de seu estudo em cursos superiores, já que a disciplina de Paleografia, antes obrigatória em cursos como Arquivologia e História, passa a ter caráter de optativa, sendo oferecida com menos frequência na graduação.

A busca por um espaço para o estudo e a prática paleográfica se justifica pelo elevado número de pesquisadores e profissionais de instituições responsáveis pela custódia de acervos documentais, como arquivos e bibliotecas, que buscam auxílio para a leitura da documentação manuscrita. Embora instituições como o Arquivo Nacional e o Arquivo Público do Estado de São Paulo ofereçam à sociedade um serviço de transcrição paleográfica para a emissão de certidões, ${ }^{16}$ é evidente, como sinaliza Oliveira (2019), a necessidade de formação de novos profissionais capazes de ler documentos antigos. ${ }^{17}$

Situação semelhante é enfrentada pela Biblioteca Nacional, instituição responsável pela gestação do primeiro curso de Biblioteconomia do país, que contava, até 1944, com o ensino de Paleografia como disciplina obrigatória (Merege, 2019), passando, posteriormente, à disciplina optativa. Nessas entidades, e certamente em inúmeras outras distribuídas pelo território brasileiro, verifica-se a demanda por pessoal qualificado na área de Paleografia, capaz de transcrever, descrever e publicar edições de documentos e coleções.

De modo a compensar, ao menos em parte, o problema do ensino formal de Paleografia nos círculos universitários, ocupam um lugar central os cursos livres, comumente chamados de Oficinas de Paleografia. Idealizadas com um fim prático direcionado à leitura de textos históricos, as oficinas desempenham um papel fundamental na capacitação de pesquisadores e servidores de arquivos e bibliotecas.

A título de ilustração, tomando por base o ano de 2019, até onde tivemos notícias contaram-se cinco oficinas de Paleografia ministradas somente na cidade do Rio de Janeiro: no Instituto de História da UFRJ, pelos Profs. Drs. Antonio Jucá e Isabelle Mello; no Arquivo Geral da Cidade do Rio de Janeiro, pela Profa . Dra. Rozely Vigas; no Arquivo Nacional, pelo Prof. Dr. Franklin Leal; na Faculdade de Letras da UFRJ, pelo Prof. Dr. Leonardo

16 No Arquivo Nacional, tal atividade é atribuída ao Setor de Reprodução e Transcrição de Documentos. http://www.arquivonacional.gov.br/br/atendimento/reproducao-transcricao-de-documentos Consulta em 20 jan 2020.

17 O adjetivo antigo é empregado neste texto em seu sentido vulgar, ou seja, não faz referência ao período da Antiguidade. 
Marcotulio; houve ainda o VI Curso de Paleografia, oferecido pelo Instituto Histórico e Geográfico Brasileiro (IHGB), também ministrado pelo Prof. Dr. Franklin Leal. Na cidade de São Paulo, foram oferecidas quatro oficinas no mesmo período: no Arquivo Público do Estado de São Paulo (APESP), pela Prof. Ms. Judie Kristie Abrahim; no Instituto de Estudos Brasileiros da USP (IEB-USP), pela Prof ${ }^{a}$. Dr ${ }^{a}$. Vanessa Monte e pelos Profs. Drs. Sílvio Toledo Neto e Phablo Fachin; na Faculdade de Filosofia, Letras e Ciências Humanas da USP (FFLCH-USP), pelo Prof. Dr. Phablo Fachin, pela Prof ${ }^{a}$. Dr ${ }^{a}$. Vanessa Monte e pela mestranda Regina Hauy; e, novamente no IEB-USP, teve lugar a oficina ministrada pelas $\operatorname{Prof}^{a}$ s. Dr ${ }^{a}$ s. Vanessa Monte e Renata Munhoz.

Às oficinas e, mais particularmente, ao ensino de Paleografia nelas desenvolvido, dedicamos as próximas seções deste artigo.

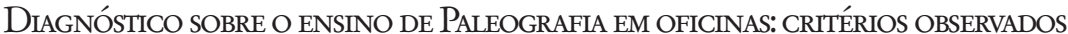

Costuma-se dividir, para fins epistemológicos, a Paleografia em três dimensões: ${ }^{18}$ a Paleografia de Leitura, a Paleografia de Análise e a História Social da Cultura Escrita (Sáez e Castillo, 2004).

A Paleografia de Leitura é aquela responsável pelo primeiro nível de contato com a materialidade gráfica do manuscrito e tem como objetivo central a leitura e a decifração corretas dos signos gráficos. A ela, podemos dizer, corresponde o surgimento da ciência em si. Lembremos que a obra de Jean Mabillon, De Re Diplomatica Libri VI, ${ }^{19}$ é considerada o primeiro arrazoado sobre Paleografia, ainda que não contenha o termo. ${ }^{20}$

A segunda dimensão é a Paleografia de Análise, que tem como objetivos a datação, a localização e o estabelecimento dos tipos gráficos utilizados. Enquanto a Paleografia de Leitura busca responder "o que está escrito?", a Paleografia de Análise persegue os seguintes questionamentos: "quando foi escrito?", "onde foi escrito?" e "como foi escrito?".

18 Autores como Sáez e Castillo (2004), por exemplo, consideram que as três dimensões da Paleografia não estariam no mesmo nível. A Paleografia de Leitura e a Paleografia de Análise são tratadas como disciplinas auxiliares de outras disciplinas, como História, Filologia, Codicologia ou Diplomática. O estatuto científico de disciplina autônoma é dado somente à última dimensão da Paleografia, a História Social da Cultura Escrita. Não entraremos, aqui, pelos limites deste texto, na polêmica sobre esse posicionamento. Cabe-nos, no entanto, assinalar que não concordamos com o caráter de auxiliaridade outorgado às duas primeiras dimensões da Paleografia, vistas como simples elementos técnicos de leitura e, eventualmente, de análise. Para uma discussão mais aprofundada sobre o tema, recomendamos a leitura de Gimeno Blay (1984).

19 Para uma abrangente e aprofundada análise sobre a obra, consultar Zouhar (2010).

20 A primeira obra a conter o termo palæographia foi Palæographia Graeca, sive de Ortu et progressu literarum graecarum..., publicada em 1708 por Bernard de Montfaucon, que era monge beneditino e conviveu com Jean Mabillon. 
A terceira dimensão é a História Social da Cultura Escrita, que seria o objetivo último da pesquisa em Paleografia. Essa dimensão, cujo surgimento é normalmente atribuído ao trabalho do grande filólogo italiano Armando Petrucci, caracteriza-se por duas perguntas fundamentais: "quem escreveu?" e "por que escreveu?". Responder a essas perguntas implica o estudo da difusão social e da função social da escrita. É nesse âmbito que se estudam, por exemplo, as práticas de leitura e escrita, que se relacionam, respectivamente, aos usos passivos e aos usos ativos da tecnologia da escritura. ${ }^{21}$

A Figura 1, tradução livre do original, de Sáez e Castillo (2004: 31), apresenta um esquema das três dimensões da Paleografia.

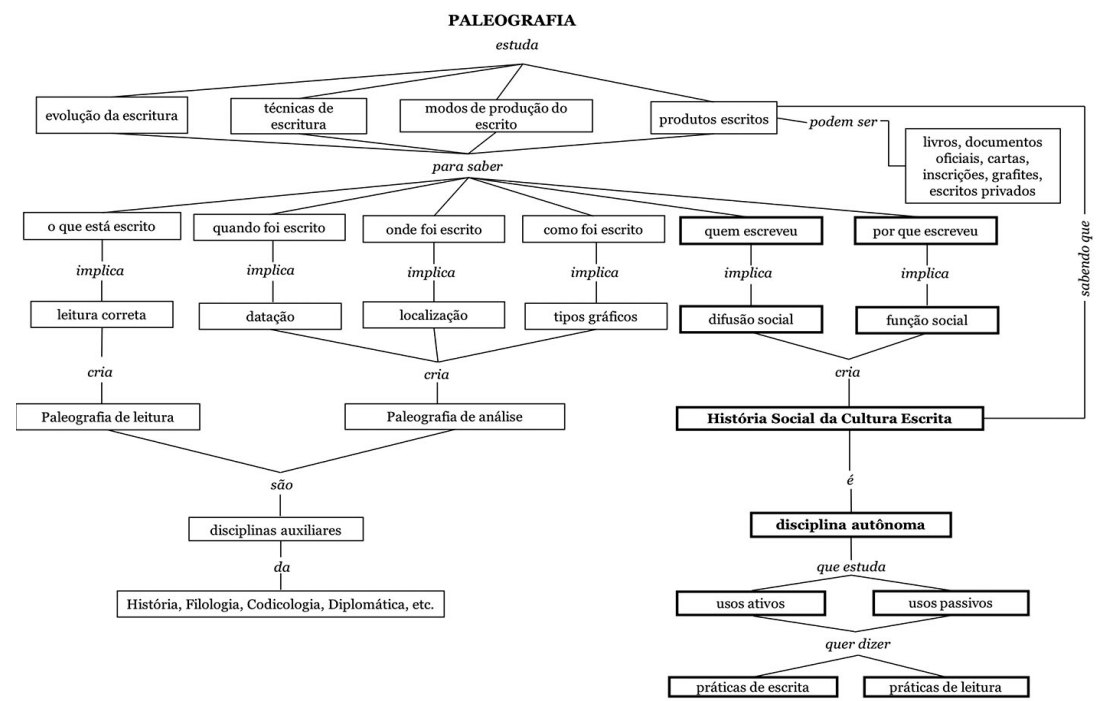

Figura 1. As três dimensões da Paleografia. Traduzido de Sáez e Castillo (2004: 31)

21 Tanto o português quanto o espanhol apresentam os significantes escrita e escritura. A diferença é, basicamente, a seguinte: no português, os dois termos podem ser tomados como sinônimos (cf. Dicionário Priberam da Lingua Portuguesa), ao passo que, em espanhol, esses vocábulos têm significados diferenciados. De acordo com o que nos ensina o Diccionario de la Real Academia Española, diferentemente de escrita, que significa o documento, a obra, a carta, o que está escrito, escritura significa a ação, o efeito, a arte de escrever. Na terminologia paleográfica brasileira o termo escrita é o eleito, enquanto escritura parece ficar mais restrito a estudos da História Social da Cultura Escrita, talvez pela expressiva produção acadêmica sobre o assunto no espanhol, sobretudo através dos trabalhos dos professores Carlos Sáez e António Castillo. Seria importante, para o avanço do conhecimento em Paleografia, fazermos a distinção também em português dos termos escrita e escritura. A escritura envolve necessariamente o processo de escrita, enquanto o termo escrita refere-se normalmente ao produto de um ato de escritura, ocultando o processo que produz esse ato. E esse processo é justamente um dos foco dos estudos paleográficos. 
Em princípio, as três dimensões da Paleografia podem ser contempladas, em maior ou menor medida, nos cursos de graduação e pós-graduação levantados anteriormente, a depender do objetivo e do direcionamento do curso, da proposta do docente, do perfil do alunado etc. No entanto, por seu caráter prático, os cursos livres ou oficinas de Paleografia costumam concentrar a atenção na primeira das dimensões, a Paleografia de Leitura, ainda que as fronteiras entre os níveis não sejam tão nítidas (e necessárias) assim. ${ }^{22}$ Por essa razão, embora o diagnóstico realizado tenha sido mais amplo de modo a descrever todas as etapas das oficinas, o foco recaiu mais especificamente sobre o ensino das atividades de leitura e decifração dos textos.

Para a realização do diagnóstico, contamos com a participação ativa dos integrantes $^{23}$ do LabEFil (Laboratório de Estudos Filológicos), grupo de pesquisa coordenado pelo Prof. Dr. Leonardo Marcotulio, na UFRJ. Durante o primeiro semestre de 2019, o desenvolvimento do projeto de extensão que culminaria na realização da Oficina de Paleografia e Edição de Textos (PalETe) levou à investigação e ao consequente levantamento de critérios a serem observados em uma oficina de Paleografia. Para tanto, foram consideradas todas as oficinas e workshops de Paleografia cursados pelos membros do grupo, na cidade do Rio de Janeiro, em modalidade presencial. Os pontos elencados foram: (i) ementa; (ii) carga horária; (iii) materiais didáticos/ bibliografia de apoio; (iv) textos; (v) atividades de leitura e transcrição; e, por fim, (vi) relação entre teoria e prática.

Ementa. Constatou-se uma ampla convergência das ementas, que geralmente partem do conceito de Paleografia, passando pelo seu histórico e chegando à evolução dos sistemas de escrita. É comum tratar-se também dos materiais e instrumentos escriptórios, além dos elementos paleográficos tradicionais, como as abreviaturas, a numeração e a pontuação. Nas ementas costuma figurar normas de transcrição e prática de leitura e transcrição de textos. No geral, a

22 A experiência docente nos revela uma dificuldade considerável dos alunos que se deparam com textos manuscritos de períodos diversos. Normalmente, parte-se do senso comum de que quanto mais antigo é um texto, mais difícil é sua decifração. A primeira tarefa, portanto, parece ser quebrar esse construto e, para isso, é imprescindível o conhecimento acerca da Paleografia de Análise, que se debruça sobre os tipos gráficos, e da História Social da Cultura Escrita, que investigará as práticas de escrita. O primeiro passo na correta decifração de um manuscrito deve ser a contextualização do documento. É preciso saber se se trata de um manuscrito avulso ou pertencente a um códice, quem o escreveu, quando foi escrito, seu estado de conservação, o fundo (ou a coleção) e o arquivo a que pertence. Em uma situação de pesquisa, essas são informações primordiais a serem investigadas, normalmente por meio dos catálogos físicos e eletrônicos, antes mesmo da tentativa de decifração.

23 Na ocasião, o LabEFil contava com uma aluna de doutorado em Letras Neolatinas: Aline Santos da Silva; dois alunos de mestrado, em Letras Neolatinas e Vernáculas: Beatriz Dias Mikhail e Daví Lopes Franco, respectivamente; quatro alunas de graduação em Letras: Maria Elisa Lima de Sousa, Letycia Dias Mallet, Catarina Romeiro e Millena Cassim; e, por fim, três alunas extensionistas: Juliana Fialho, Vitória Pedro e Caroline Ferreira. 
parte teórica é bem sistematizada, enquanto os elementos paleográficos são apresentados ora em aulas expositivas, ora de forma prática, durante a leitura dos textos. Como era de se esperar, nota-se uma diversidade das normas de transcrição utilizadas nas diferentes oficinas e workshops.

Carga horária. A carga horária costuma variar entre 2 e 60 horas. O tempo dedicado aos cursos também está diretamente relacionado à categoria atribuída: cursos mais curtos foram comumente nomeados como workshops, ao passo que os mais extensos receberam a designação de curso ou oficina.

Materiais didáticos/Bibliografia de apoio. Cabe destaque a ausência de materiais didáticos voltados exclusivamente para o ensino de paleografia, lacuna suprida por diversos materiais de apoio, geralmente elaborados pelos próprios ministrantes. As obras mais frequentemente adotadas como bibliografia de apoio são Berwanger e Leal (2015), Acioli (1994), Núñez Contreras (1994) e Mendes (1953). É bastante utilizado o glossário de Leal (1994). Os dicionários de abreviaturas mais recorrentes são o de Nunes (1980) e de Flexor (2008). As lâminas paleográficas também costumam marcar presença: são exemplos a obra de Dias, Marques e Rodrigues (1987) e a de Nunes (1969). Além disso, os manuscritos utilizados nas aulas eram extraídos de corpora variados disponíveis online, como é o caso do Projeto P.S. Post Scriptum (http://ps.clul.ul.pt).

Textos. Quanto aos critérios de seleção dos textos manuscritos usados como objeto para a prática de leitura e transcrição, encontra-se uma ampla variedade: a ausência de um recorte, procedendo-se à seleção aleatória de textos; o recorte temporal; o recorte temático ou tipológico; o recorte por tipos de letras (gótica e humanística, por exemplo); além do recorte por graus de dificuldade. A quantidade de textos é bastante variável, indo de 1 a 30 documentos. Os textos escolhidos se apresentavam ora completos ora fragmentários, a depender da oficina. A informação arquivística nem sempre esteve presente. A sequência de trabalho com os textos também se mostrou bastante variável: ordem aleatória, ordem temporal (do mais recente ao mais antigo, e vice-versa), ordem temática (certidões de nascimento, de batismo, de casamento e de óbito, por exemplo) ou ordem de acordo com o nível de dificuldade (do mais fácil para o mais difícil, e vice-versa).

Atividades de leitura e transcrição. Quanto às atividades de leitura e transcrição, houve oficinas em que se praticaram somente atividades de leitura e outras em que foram propostas ambas as atividades. Nas atividades de transcrição, houve casos em que não se usou nenhum conjunto de normas e casos em que as normas apresentadas no módulo teórico não foram utilizadas na atividade de transcrição. Em algumas oficinas, no entanto, as mesmas nor- 
mas do módulo teórico foram empregadas no módulo prático. $\mathrm{O}$ acesso aos textos se deu de forma diversa: em aula, com fotocópia em preto e branco, em formato A3 ou A4, com e sem projeção na tela. Em algumas oficinas os alunos só dispunham da projeção na tela. Em outras, os alunos tinham acesso aos fac-símiles enviados por email, antes ou depois das aulas. Especificamente em relação à condução da leitura, que ocorreu geralmente como atividade prévia à transcrição, quando houve alguma instrução, ela consistia do comando: "Leiam e transcrevam o texto". Notou-se, de forma geral, a ausência de um procedimento que guiasse a leitura dos textos. A correção da leitura e da transcrição foi realizada de modo diverso: pela leitura do professor, pela leitura em coro dos alunos ou pela leitura individual do aluno, a quem se atribuía uma linha do documento manuscrito.

Relação entre teoria e prática. Sobre a relação entre teoria e prática, algumas vezes não se notou uma relação explícita e em outras percebeu-se que havia apenas uma relação parcial, sobretudo no que diz respeito a aspectos paleográficos, como as abreviaturas.

Durante a realização da pesquisa, alguns depoimentos de membros do grupo chamaram a atenção: "As oficinas de paleografia diferem entre si em função de quem a ministra: historiadores, arquivistas e filólogos dão oficinas completamente diferentes"; "Oficinas de paleografia são sempre de nível básico. Onde estão as oficinas de níveis intermediário e avançado?"; "Senti uma quebra abrupta: teoria de um lado, a prática de outro, sem nenhum tipo de conexão"; "Sempre faço novas oficinas porque nunca lembro do que aprendi. Tenho a sensação de que não há uma construção 'vertical' do conhecimento"; "Não me lembro de nenhum texto lido. Li, mas não entendi nada. Para ser sincero, não sei do que tratavam os textos". Esses relatos, de extrema importância para a formatação de um novo modelo de oficina de Paleografia, apontam para aspectos positivos, como a multidisciplinaridade inerente à área, mas também para aspectos negativos. Em síntese, as duas principais ausências verificadas foram: a falta de materiais didáticos específicos para o ensino de Paleografia e a falta de procedimentos e estratégias para a leitura dos textos. ${ }^{24}$

24 Embora não houvesse uma metodologia propriamente dita, havia uma série de procedimentos praticados, depreendida do trabalho de leitura executado: 1) o professor distribuía e/ou projetava o texto; 2) o professor pedia que os alunos lessem e/ou transcrevessem o texto; 3 ) os alunos liam o texto em silêncio e faziam a transcrição; 4) o professor corrigia o exercício de leitura e/ou transcrição. Pela sequência utilizada, parte-se do princípio de que o aluno conseguiria ler o texto ou, ao menos, partes do texto, embora tivesse algumas dificuldades. Durante a correção do exercício, o trabalho do professor consistia em verificar o que o aluno foi capaz de ler e auxiliá-lo a superar os obstáculos de leitura, que podiam ser de diversas naturezas, como grafemas com traçados distintos dos atuais, alógrafos, sinais de pontuação, enlaces, ligaduras, nexos, abreviaturas, numerais etc. 
De fato, contamos com uma escassa produção de materiais didáticos para o ensino de Paleografia. Até onde se tem notícia, o único material didático para esse fim escrito em português é praticamente desconhecido, embora tenha sido impresso no Brasil. Intitula-se Paleografia Portuguesa Básica, tendo sido publicado em 1978 pelo Departamento de História da Família d'A Igreja de Jesus Cristo dos Santos dos Últimos Dias, Série H, No 20.

Já em relação aos procedimentos para a leitura de textos, uma observação se faz necessária. É preciso que diferenciemos método em Paleografia de Leitura, por um lado, e estratégias (didáticas) de leitura de textos manuscritos, por outro. Como mostraremos na próximo seção, há um método que, de certa forma, foi observado em todas as oficinas consideradas em nossa amostra. O problema detectado refere-se às atividades de leitura e transcrição, que não apresentavam comandos e orientações específicas. Além disso, não se verificou o desenvolvimento de uma didática própria que indicasse ao aluno, por exemplo, os graus de avanço em sua capacidade leitora. Tratemos, primeiramente, da questão do método e, em sequência, de uma proposta de estratégias de leitura.

\section{UM MÉTODO PARA A LEITURA DE TEXTOS ANTIGOS}

A utilização de um método de leitura é de extrema importância para o ensino de Paleografia. De acordo com Casado Quintanilla (2016: 12), "sempre é necessário seguir um bom método de trabalho em qualquer ocasião e para qualquer temática. A Paleografia é uma disciplina que ao aluno ou a qualquer leitor de documentos históricos parece de difícil aprendizagem, motivo mais do que suficiente para tratar com detalhe o tema do método de estudo". ${ }^{25}$ Para o autor, é a partir da utilização de um método sólido que o aspirante a paleógrafo adquirirá "as destrezas necessárias para ler com soltura os documentos com os quais terá que enfrentar para realizar qualquer investigação histórica, sempre que queira trabalhar sobre documentos de arquivo no próprio arquivo e não confiar nas transcrições já realizadas" (Casado Quintanilla, 2016: 12).

25 Para facilitar a exposição e divulgar textos clássicos escritos em espanhol a leitores de língua portuguesa, os originais, em espanhol, foram, por nós, traduzidos ao português. 
Marín Martínez (1988: 31-32) ${ }^{26}$ talvez seja o primeiro autor a sistematizar um método para a leitura de textos antigos. Por método, entende-se uma série de princípios teóricos e procedimentos práticos que devem ser observados e seguidos, respectivamente, para que se cumpram as três finalidades da $\mathrm{Pa}$ leografia, isto é, as suas três dimensões. Em relação à primeira delas, mais diretamente voltada à decifração e à leitura correta dos textos, devem-se seguir alguns princípios teóricos como normas para uma leitura paleográfica:

1. Ler sem pressa e sem angústia, com espírito sossegado e com atenção suficiente, mas não excessiva nem, muito menos, tensa. Mal inimigo da boa leitura será, pois, qualquer tipo de nervosismo, tanto o temperamental e permanente, quanto o esporádico, seja qual for a razão. [...]

2. Não ler jamais de memória nem distraidamente, confiando o leitor em seu conhecimento de textos iguais ou parecidos. É uma norma que se há de ter especialmente em conta para a leitura habitual de séries documentais, nas quais a fraseologia do texto varia pouco de uns documentos a outros. É importante, por exemplo, controlar as possíveis erratas do texto que se lê e transcreve; mas se a operação de leitura se realiza de forma rotineira e de memória, a falha é algo certo em relação às erratas às quais se refere.

3. Não prescindir de nenhum elemento gráfico, por mais insignificante que pareça. O leitor paleógrafo não se pode contentar em ler o texto principal de seu conjunto escrito e depreciar o resto; até o sinal mais exíguo deve ser objeto de sua atividade leitora e, em consequência, fazer tudo o que for possível para saber o que significa e, se não significa nada, por que foi traçado e por que está ali.

4. Não ter a pretensão de querer ler o texto escrito de uma só vez, sobretudo se se trata de textos longos e escrituras difíceis ou mais desconhecidas. Em princípio, pouco importa que à primeira tentativa $\mathrm{e}$ à segunda restem palavras ou frases que não foram satisfatoriamente lidas; essas questões serão resolvidas na segunda ou terceira leitura, ou até mesmo nas leituras posteriores.

26 As obras de referência sobre Paleografia, de forma geral, e sobre o método de leitura paleográfica, de forma mais específica, estão escritas majoritariamente em língua espanhola. Chama a atenção o fato de não haver, em língua portuguesa, bibliografia de cunho mais teórico especializada em Paleografia. Tangenciando a problemática dos métodos em Paleografia de Leitura, estão disponíveis, em português, trabalhos que se dedicam mais especificamente às dificuldades encontradas na leitura, sobretudo de textos medievais, como Mendes (1952), A Paleografia e as suas Dificuldades; Mendes (1953), Noções de Paleografia; e Silva Neto (1956), Textos medievais portuguêses e seus problemas. Nessas obras, são elencadas possíveis dificuldades de leitura que precisam ser enfrentadas pelo pesquisador. São, de forma geral, referentes ao vocabulário, aos fatos linguísticos, à grafia, às abreviaturas e à caligrafia usada, com especial destaque às letras que podem ser confundidas, por apresentarem morfologias semelhantes. 
5. Possuir conhecimento suficiente da língua na qual o texto está escrito e ter ideia, ainda que seja mínima, do assunto ao qual o texto se refere. Quando se tratar de textos longos sobre assuntos muito específicos, como medicina, matemática, direito, na maioria dos casos será inútil que um profano em tais assuntos tente lê-los. [...] Se à especificidade do texto for somado um grau extraordinário de escrita ilegível ou dificultosa [...], poucos, ou quase ninguém, conseguirão lê-los diretamente.

6. É preciso ter um cuidado particular com os nomes próprios de pessoas, de aldeias, de termos geográficos etc., ou de palavras típicas e menos correntes que se repitam no texto lido. Precisamente nessa repetição e na mútua comparação das passagens onde a palavra se repete, o leitor encontrará apoio não depreciável para encontrar a leitura verdadeira.

7. Será necessária preparação, assim como meios para abordar a leitura e interpretação das chamadas escritas cifradas ou criptográficas, ou seja, aquelas que, prescindindo das figuras próprias e normais de cada letra, reduzem as sílabas, as palavras e ainda as frases inteiras a signos estranhos e convencionais. Qualquer tentativa espontânea de lê-las será inútil se previamente não se dispõe de alguma chave que explique tais signos.

8. Não aceitar sistematicamente como boas possíveis leituras anteriores. O leitor que atua como paleógrafo deve, ao menos, comprovar diretamente e por conta própria que o texto correspondente foi bem lido anteriormente. [...]

9. A operação de ler qualquer texto um pouco longo deve ser realizada por escrito, ou seja, que a leitura se converta de algum modo em transcrição e cópia do que se lê. (Marín Martínez, 1988: 31-32.)

Para que se conheça bem um determinado tipo de escritura e se possa lê-la com confiança, é preciso, segundo Marín Martínez (1988: 32-33), adotar os seguintes procedimentos práticos:

a) O leitor iniciante deverá observar primeiramente e tratar de fixar em sua memória as formas típicas de cada letra, ou seja, sua figura ou desenho, consideradas isoladamente, com independência uma da outra. Para aprendê-las, utilizará aqueles livros (manuais, cartilhas, abecedários, regras etc.) onde venham fielmente reproduzidas tais letras. Para fixá-las em sua memória, como um meio muito eficaz, pode-se ir buscando, uma por uma, tais figuras dentro do texto que se 
deseja ler e ir identificando-as como tais letras, independentemente do sentido que possam ter com relação à palavra ou sílaba respectiva.

b) Uma vez aprendidas na teoria e na prática as formas de cada letra sozinha e isolada, deve-se passar em seguida a fazer o mesmo com as figuras ou desenhos correspondentes às ligações ou uniões de duas, três ou mais letras que, normalmente, se dão em qualquer conjunto escrito e que contribuem para deformar as formas primitivas e autênticas daquelas.

c) Passar logo, por procedimento análogo, ao aprendizado de todos os demais sinais gráficos que não sejam letras nem ligações, mas que servem para completar o sentido daqueles (sinais de numeração, de pontuação, de interrogação etc.). Entre esses sinais serão objeto de atenção especial os chamados sinais abreviativos [...].

d) Uma vez assimilados todos esses elementos que integram o fenômeno da escrita, não resta nada para o aprendiz de leitor para começar uma prática constante e ordenada de leitura, começando pelos conjuntos escritos mais fáceis e passando gradualmente aos mais difíceis.

Ainda de acordo com o autor, devido à sua simplicidade, o método explicitado pode ser comparado ao método empregado no processo de alfabetização de crianças. A diferença entre a criança e o aprendiz de paleógrafo estaria exatamente na maior capacidade de reflexão deste último, que terá de evitar qualquer tipo de automatismo em sua atividade de leitura.

O método em Paleografia de Leitura, sistematizado na obra de Marín Martínez (1988), aparece registrado, com mais ou menos detalhes, na íntegra ou com algumas adaptações, em obras posteriores, como Galende Díaz, Cabezas Fontanilla e Ávila Seoane (2016) e Casado Quintanilla (2016), somente para citar alguns exemplos. De forma geral, os autores coincidem ao afirmar que o paleógrafo iniciante deve considerar princípios teóricos e adotar procedimentos práticos. Sobre os princípios, é recomendável que a leitura de textos de épocas pretéritas se faça sempre acompanhada da transcrição, de forma lenta, sem pressa, não prolongada, considerando todos os elementos gráficos. É importante que se tenha em mente que, em muitas ocasiões, serão necessárias diversas tentativas de leitura, em muitas das quais o paleógrafo terá de conviver com múltiplos espaços em branco em sua transcrição. É igualmente importante que se tenha conhecimentos, ainda que básicos, sobre o estado de língua, o assunto e o gênero do texto, assim como sobre a onomástica (antropônimos e topônimos). No que se refere aos procedimentos, convém entender dois momentos distintos, que podem coexistir ou ser aplicados de forma sequencial. Por um lado, é fundamental que haja um estudo sólido, por meio de manuais especializados, de modo que o estudante aprenda a reconhecer letras isoladas, enlaces, nexos, ligaduras, bem como outros elementos gráficos (sistemas de 
numeração, pontuação, abreviaturas). Ademais, o estudo deve ser acompanhado pela prática constante de leitura, de forma que o paleógrafo adquira as destrezas necessárias para a correta decifração dos manuscritos. Em síntese, para que a leitura paleográfica aconteça, é preciso que o estudo seja aplicado ao reconhecimento das formas gráficas de um texto.

É possível dizer, assim, que o método específico da disciplina Paleografia de Leitura esteve presente, em maior ou menor medida, em todas as oficinas de nossa amostra. Contudo, a depender da formação do instrutor, da carga horária do curso e do perfil do público, alguns princípios e procedimentos puderam ser mais facilmente detectados que outros.

\section{Para além do método: uma proposta de estratégias de leitura}

Se, por um lado, o método pode ser, de certa forma, observado, o mesmo não pode ser dito sobre estratégias didáticas aplicadas especificamente às atividades de leitura em oficinas de Paleografia. De modo a preencher essa lacuna, destacamos uma obra recentemente publicada que poderia trazer alguma luz a essa discussão.

Em Filologia, história e lingua: olhares sobre o português medieval, interessados em abordar as diversas atividades que devem ser desenvolvidas por pesquisadores interessados no português do período medieval, isto é, os diversos olhares, Marcotulio et al. (2018), nos capítulos dedicados ao labor filológico de leitura e edição de textos, oferecem uma proposta de leitura de textos, com atividades diferenciadas em função do grau de dificuldade de leitura. Os textos remanescentes podem, assim, ser divididos, para fins didáticos, em dois grandes grupos: textos de leitura imediata e textos de difícil leitura. O critério que distingue os dois grupos, com um certo grau de subjetividade, leva em consideração basicamente questões como caligrafia e legibilidade: textos de leitura imediata têm letras claras, bem traçadas e podem ser lidos facilmente; por outro lado, textos de difícil leitura são caracterizados por apresentarem uma escrita menos caligráfica, que dificulta a leitura e o entendimento do texto.

Com base nessa classificação, e respeitando a proposta didática da obra, o primeiro capítulo, intitulado "Edição filológica: preparação de textos para o estudo da história da língua", foi pensado a partir de dois textos de leitura imediata: um texto atual extraído de um aplicativo de mensagens instantâneas $;{ }^{27} \mathrm{e}$ um bilhete amoroso escrito nos inícios do século XX.

27 Com o texto do aplicativo de mensagens estantâneas, o objetivo dos autores é introduzir o leitor no universo do labor filológico. São, assim, tratados conceitos básicos para a Filologia, como tipos de edição, finalidades, público-alvo e intervenções realizadas. Pela facilidade de leitura, não são trabalhadas atividades específicas para esse fim. 

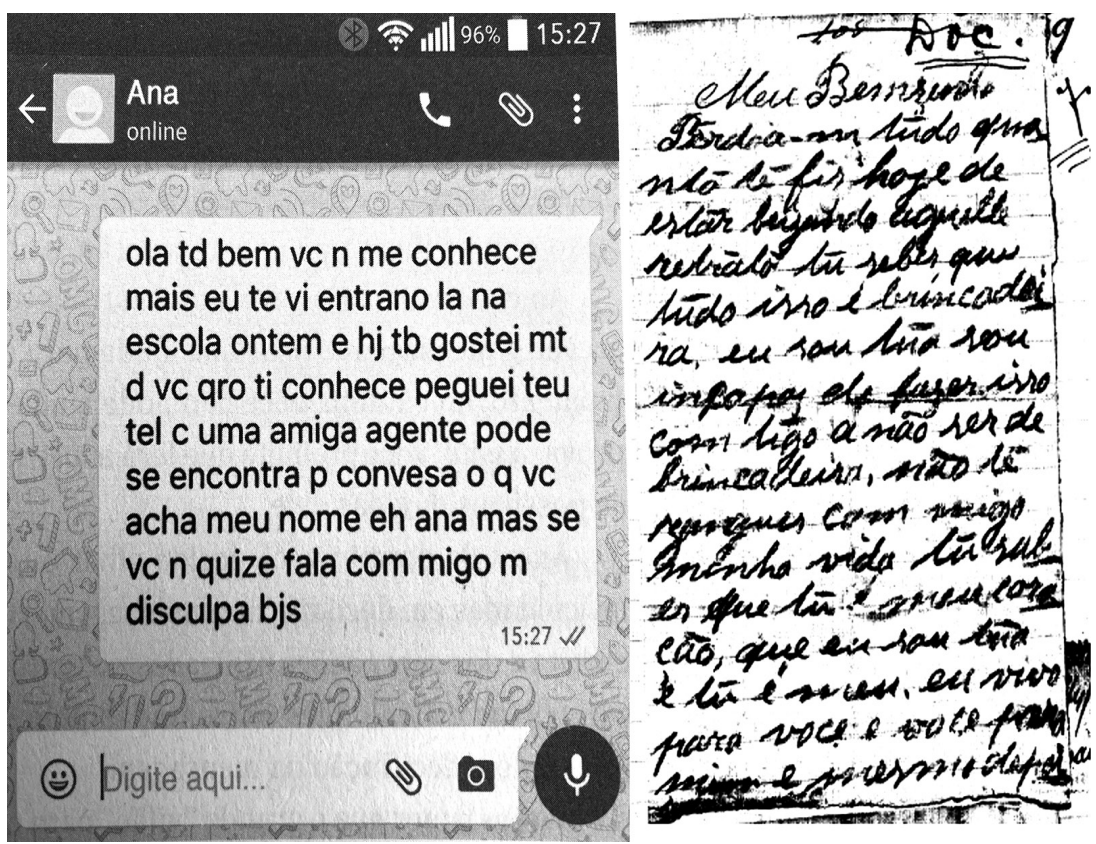

Figura 2. Texto de aplicativo de mensagens instantâneas (esquerda) e bilhete novecentista (direita) Fonte: Marcotulio et al. (2018: 33; 41)

Embora o texto novecentista pudesse trazer dificuldades pontuais de leitura, as questões paleográficas para a decifração dos signos gráficos não invalidariam a imediatez da leitura. Ainda assim, de modo a guiar o leitor, são oferecidas informações relevantes relacionadas a atividades especificas como, por exemplo, o conceito de palavra e os recursos para a sua identificação, a identificação de letras através da busca de letras semelhantes, a leitura por inferência a partir de recursos gramaticais e a elaboração de listas de palavras lidas. Também são oferecidas orientações específicas para a detecção de possíveis problemas de leitura, como as dificuldades referentes ao reconhecimento de certas letras, à junção e à segmentação de palavras que se distanciam do padrão atual. Para cada uma dessas questões são oferecidas atividades guiadas e sugestão de respostas.

O segundo capítulo da obra, "Leitura e edição de textos medievais", é o responsável por trazer um texto de difícil leitura: uma cantiga medieval galego-portuguesa (Figura 3). Textos medievais escritos em letra gótica, ainda que apresentem "boa caligrafia", também podem ser classificados por leitores iniciantes como textos de difícil leitura, pelo desconhecimento de escritas distintas da contemporânea. 


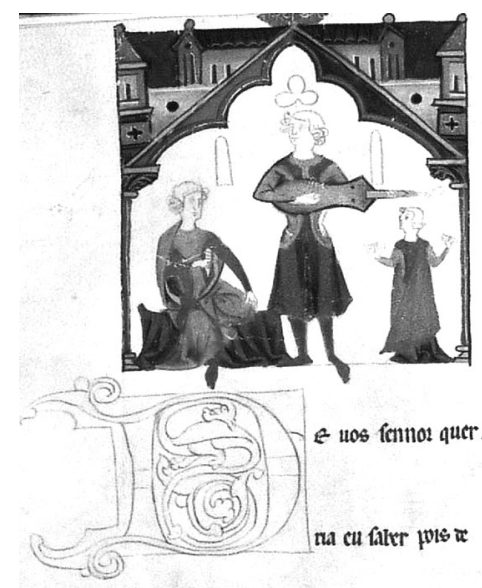

foutas ma moat ateî. c cal non motr

quema moirt que me digares que for

mí en p.

on mis mort me fera tran txn.

por que fer at us parattu on.

efols non mout ulent attos pien.

ute med digatios que fater ou v.

o: ma moar que uo w atechr.

trucu a d's fenp? c non mu girar

c ucturo to mua fénos pgontan:

ue me digarxs que faxt ai y

of inta morte togrict de camer

c no inta ann por the fizor pros.

eflar connofque uenn a tos fènos

que me digaros que fatm eur.

Figura 3. Texto medieval: cantiga n. 111, de João Nunes Camanês, Cancioneiro da Ajuda

Fonte: Marcotulio et al. (2018: 56)

Para se trabalhar o texto selecionado, os autores propõem estratégias de leitura com base no estabelecimento de níveis:

1. Nível de Compreensão literal
1.1 Nível filológico-paleográ-
fico
1.2 Nível linguístico-lexical
2. Nível de Compreensão literária


Por se tratar de uma obra literária, subdivide-se a compreensão do texto em dois grandes níveis: compreensão literal e compreensão literária. A compreensão literal, de especial interesse à Paleografia de Leitura, é ainda subdividida em níveis menores, a saber: nível filológico-paleográfico e nível linguístico-lexical.

Há objetivos específicos para cada nível estabelecido. No primeiro deles, Compreensão literal. Nível filológico-paleográfico, a preocupação recai sobre a decifração do texto. São abordados os seguintes aspectos: suporte; iluminuras e letras capitulares; palavras, grafemas e alógrafos; segmentação e junção de palavras; elisão vocálica; omissão de grafemas; abreviaturas; polimorfismo gráfico; pontuação; e, por fim, uso de maiúsculas e minúsculas. Para cada um desses temas, são propostas atividades guiadas com explicações básicas e tarefas a serem executadas. Posteriormente, oferece-se uma sugestão de resposta. A título de ilustração, para tratar de palavras, grafemas e alógrafos, a seguinte sequência pode ser observada:

1. Informação inicial. "No plano da escrita, uma palavra seria um sinal ou um conjunto de sinais gráficos. Esses sinais, comumente conhecidos pelo nome mais geral de letras, são tecnicamente denominados de grafemas, unidades mínimas pertencentes ao sistema grafemático" (Marcotulio et al., 2018: 60).

2. Exercício. "Antes, no entanto, de apresentar os grafemas que mais chamam a atenção dos leitores de hoje em dia, vamos fazer o mesmo exercício que fizemos com o bilhete. Leia a cantiga e transcreva todas as palavras e sequências que conseguir, deixando um espaço para as passagens de difícil decifração" (Marcotulio et al., 2018: 60).

3 Sugestão de resposta. "Em primeiro lugar, você deve ter observado a presença clara de espaços entre algumas sequências de letras que poderiam ser, em princípio, palavras. Após a sensação inicial de dificuldade para proceder à leitura do manuscrito, você notou que algumas sequências podem ser facilmente decifradas por um leitor moderno. Em outros momentos, no entanto, pode ser que consigamos entender as letras, mas não sejamos capazes de atribuir um significado a determinada sequência. Essa sensação é completamente normal quando enfrentamos um texto medieval pela primeira vez. $\mathrm{O}$ primeiro passo consiste exatamente em decifrar as letras de determinada sequência; posteriormente, voltamos ao texto para capturar seu sentido e significado. Após esse primeiro exercício, é bastante provável que você tenha sido capaz de reconhecer as seguintes palavras e/ou sequências [...]" (Marcotulio et al., 2018: 60). 


\begin{tabular}{|c|c|c|}
\hline LINHA & \multicolumn{2}{|c|}{ PALAVRa } \\
\hline \multirow{2}{*}{2} & cll & $\mathrm{eu}$ \\
\hline & pls & pois \\
\hline \multirow{5}{*}{3} & mla & mia \\
\hline & $c$ & $\mathrm{e}$ \\
\hline & cul & eu \\
\hline & non & non \\
\hline & $e$ & $\mathrm{e}$ \\
\hline \multirow{3}{*}{4} & que & que \\
\hline & me & me \\
\hline & que & que \\
\hline 5 & ell & eu \\
\hline \multirow{3}{*}{6} & mla & mia \\
\hline & me & me \\
\hline & ben & ben \\
\hline \multirow{2}{*}{7} & que & que \\
\hline & en & en \\
\hline \multirow{3}{*}{8} & $\mathfrak{c}$ & $\mathrm{e}$ \\
\hline & pDIS & pois \\
\hline & non & non \\
\hline \multirow{3}{*}{9} & me & me \\
\hline & que & que \\
\hline & ct & eu \\
\hline
\end{tabular}

\begin{tabular}{|c|c|c|}
\hline \multirow{2}{*}{10} & thlat & mia \\
\hline & que & que \\
\hline \multirow{4}{*}{11} & $\boldsymbol{A}$ & $a$ \\
\hline & $\boldsymbol{e}$ & e \\
\hline & non & non \\
\hline & mia & mia \\
\hline \multirow{2}{*}{12} & $e$ & e \\
\hline & mia & mia \\
\hline \multirow{3}{*}{13} & me & me \\
\hline & que & que \\
\hline & ell & eu \\
\hline \multirow{2}{*}{14} & mia & mia \\
\hline & $e$ & $\mathrm{e}$ \\
\hline \multirow{3}{*}{15} & e & e \\
\hline & mia & mia \\
\hline & the & me \\
\hline 16 & $\boldsymbol{A}$ & $a$ \\
\hline \multirow{4}{*}{17} & que & que \\
\hline & the & me \\
\hline & que & que \\
\hline & eu & eu \\
\hline
\end{tabular}

Figura 5. Marcotulio et al., 2018: 60-61

Após essa atividade, um novo ciclo é iniciado, tratando, dessa vez, do fenômeno da alografia, do plano mais teórico ao prático, de modo que o quadro de palavras decifradas por linha se torne cada vez mais completo.

Uma vez superadas as questões do primeiro nível de leitura, inicia-se, com a mesma metodologia de trabalho, o segundo nível de compreensão literal: nível linguístico-lexical. Nesse nível são abordados aspectos grafo-fonéticos, morfossintáticos e lexicais do texto medieval. Como já apontado anteriormente, quando tivemos a oportunidade de apresentar o método em Paleografia de Leitura, conhecer o estado de língua do texto é fundamental para uma boa leitura. 
Observa-se, assim, uma transição entre os dois primeiros níveis: da decifração passa-se ao entendimento do texto. Por se tratar de um texto literário, o ciclo se fecha no próximo nível de leitura, nível de compreensão literária, responsável por sua interpretação.

A proposta de estratégias de leitura a partir de níveis elaborada por Marcotulio et al. (2018), embora tenha sido pensada para um texto medieval específico, poderia muito bem ser replicada em outros textos considerados como de difícil leitura. O estabelecimento de níveis é de fundamental importância na proposta, de modo a guiar, com fins didáticos, o aprendiz no processo de leitura de textos antigos, através de uma sequência didática com objetivos, atividades (e, por que não dizer, expectativas) definidos. Cabe deixar claro que o conceito de leitura adotado extrapola o limite da decifração. Ler é transcrever. Ler é decifrar. Mas ler também é entender e interpretar os textos.

\section{Considerações finais}

Com o breve levantamento que fizemos com base na docência posta em prática em São Paulo e no Rio de Janeiro no decorrer do ano de 2019, esperamos ter contribuído para o início da construção de um mapeamento sobre o ensino de Paleografia no Brasil. É necessário que novos mapeamentos parciais sejam feitos, para que se tenha, em um futuro breve, um mosaico menos fragmentado. A construção de um panorama mais completo sobre o ensino de Paleografia no Brasil permitirá a comparação dos resultados obtidos com os que já estão descritos para outros países, como Espanha e Portugal, por exemplo.

Pretendemos, também, ter deixado clara neste artigo a necessidade de um fluxo crescente e contínuo de oferecimento de disciplinas específicas de Paleografia nos currículos dos cursos de graduação e de pós-graduação Brasil afora, para a formação de pesquisadores e pessoal qualificado.

Além do estudo teórico da disciplina Paleografia, é fundamental que se fomente o campo de pesquisa em Ensino de Paleografia. Uma consequência direta dessa ação seria o suprimento da carência de materiais didáticos e o aperfeiçoamento de técnicas de trabalho de leitura de textos, o que enriqueceria, sem dúvidas, o ensino de Paleografia em cursos e oficinas.

Para tanto, argumentamos que o maior diálogo entre a Paleografia e a Filologia, que tem se mostrado bastante frutífero para a constituição de corpora e para o conhecimento da história da língua -bem como da história social da escrita-, permite-nos ampliar o escopo do que tradicionalmente se vem considerando como prática a ser desenvolvida no âmbito da Paleografia de 
leitura. Mais do que simplesmente uma disciplina auxiliar da História, a Paleografia permite que se torne legível qualquer texto confeccionado com escrituras em desuso aos leitores de hoje, o que pode ser proporcionado com estratégias de leitura que considerem níveis distintos que, de forma consecutiva, incidam sobre as etapas de leitura, decifração e transcrição, assim como sobre a compreensão global e mais detalhada do texto.

$\mathrm{O}$ avanço e o fortalecimento da área, como um todo, poderiam gerar condições propícias para que no Brasil, dada a sua expressiva massa documental conservada em acervos arquivísticos, se estimulasse a produção bibliográfica em Paleografia.

\section{REFERÊNCIAS}

Acioli, V. L. C. 1994. A Escrita no Brasil Colônia: um guia para leitura de documentos manuscritos. Recife: FUNDAJ, Editora Massangana, UFPE, Editora Universitária.

Berwanger, A. R. e J. E. F. Leal. 2015. Noções de Paleografia e de Diplomática, 5 a ed. Santa Maria: Editora UFSM.

Borges, L. e A. Silva. 2018. "Transcrições em linha: elearning de Paleografia em arquivos europeus”. Revista Portuguesa de História (49): 31-54. https://doi.org/10.14195/0870-4147_49_2

Cárcel Ortí, M. M. 1996. La enseñanza de la Paleografía y Diplomática. Centros y Cursos. Valencia: Artes Gráficas Soler.

Casado Quintanilla, B. 2016. Paleografía. Nociones básicas para leer documentos conservados en los archivos bistóricos, 3a ed. Madrid: Confederación Española de Centros de Estudios Locales (CECEL).

Company Company, C. 1994. Documentos lingüísticos de la Nueva España. Altiplano Central. México: UNAM.

Cruz, A. 1966. "Observações sobre o estudo da paleografia em Portugal”. Cale: Revista da Faculdade de Letras do Porto, 173-233.

Dias, J. J. A., A. H. de O. Marques e T. F. Rodrigues. 1987. Álbum de Paleografia. Lisboa: Editorial Estampa.

Flexor, M. H. O. 2008. Abreviaturas: manuscritos dos séculos XVI ao XIX, 3a ed. Rio de Janeiro: Arquivo Nacional.

Galende Díaz, J. C., S. Cabezas Fontanilla e N. Ávila Seoane, coords. 2016. Paleografía y escritura hispánica. Madrid: Editorial Síntesis.

Gimeno Blay, F. M. 1984. Las llamadas ciencias auxiliares de la Historia ¿Errónea interpretación? (Consideraciones sobre el método de la investigación en Paleografía). Zaragoza: Cuadernos de Historia Jerónimo Zurita 51-52.

Leal, J. E. G. F. 1994. Glossário de Paleografia. Rio de Janeiro: Associação dos Arquivistas Brasileiros.

Marcotulio, L. L., C. Lopes, M. Bastos e T. Oliveira. 2018. Filologia, história e língua: olhares sobre o português medieval. São Paulo: Parábola.

Marín Martínez, T., org. 1988. Paleografía y Diplomática, 3a ed. Vol. I e II. Madrid: Universidad Nacional de Educación a Distancia. 
Mendes, U. D. 1952. A Paleografia e as suas Dificuldades. Separata do vol. 10 do Boletim do Departamento do Arquivo do Estado. São Paulo.

Mendes, U. D. 1953. Noções de Paleografia. São Paulo: Departamento do Arquivo do Estado de São Paulo, Secretaria da Educação.

Merege, A. 2019. "Desafios e perspectivas frente aos manuscritos da Biblioteca Nacional”. LaborHistórico 5 (2): 231-248. https://doi.org/10.24206/lh.v5i2.24922

Nunes, E. B. 1969. Álbum de Paleografia Portuguesa. Vol. I. Lisboa: Instituto de Alta Cultura.

Nunes, E. B. 1980. Abreviaturas paleográficas portuguesas. Lisboa: ABRE.

Núñez Contreras, L. 1994. Manual de Paleografía. Fundamentos de la escritura latina basta el siglo VIII. Madrid: Cátedra.

Oliveira, C. 2019. "A Paleografia em prática no Arquivo Nacional: a leitura da escrita antiga na contemporaneidade". LaborHistórico 5 (2): 213-230. https://doi.org/10.24206/lh.v5i2.26450

Sáez, C. e A. Castillo. 2004. "Paleografía e Historia de la Cultura Escrita: del signo a lo escrito”, en Introducción a la Paleografía y la Diplomática General, editado por A. Riesco Terrero, 21-31. Madrid: Editorial Síntesis.

Sánchez Prieto-Borja, P. 1991. Textos para la historia del español. Vol. I. Reproducción facsímil, transcripción paleográfica, presentación crítica y comentario lingüístico de documentos medievales y de los siglos XVI y XVII. Alcalá de Henares: Universidad de Alcalá de Henares.

Santiago Fernández, F. J., coord. 2016. Catálogo de asignaturas del área de Ciencias y Técnicas Historiográficas en la universidad española. Madrid: Sociedad Española de Ciencias y Técnicas Historiográficas. Acesso em 10 set 2020.

http://cartulario.es/wp-content/uploads/2018/02/2016-CAT\%C3\%81LOGO-ASIGNATURAS-CCTTHH-UNIVERSIDADES-ESPA\%C3\%91OLAS-ilovepdf-compressed.pdf

Santiago Fernández, F. J. e J. M. López Villalba, coords. 2014. Catálogo de asignaturas del área de Ciencias y Técnicas Historiográficas en la universidad española. Madrid: Sociedad Española de Ciencias y Técnicas Historiográficas. Acesso em 10 set 2020. http://cartulario.es/wp-content/uploads/2018/02/2014_CAT\%C3\%81LOGO-ASIGNATURAS-CCTTHH-UNIVERSIDADES-ESPA\%C3\%91OLAS-ilovepdf-compressed1.pdf

Santos, M. J. A. 2000. Ler e compreender a escrita na Idade Média. Lisboa: Edições Colibri.

Silva Neto, S. 1956. Textos medievais portuguêses e seus problemas. Rio de Janeiro: Ministério da Educação e Cultura / Casa de Rui Barbosa.

Zouhar, J. 2010. "De re diplomatica libri sex by Jean Mabillon in outline". Listy filologické (3-4): 357-388. Acesso em 02 mar 2020. https://www.researchgate.net/publication/260161791_De_Re_Diplomatica_Libri_Sex_by_Jean_Mabillon_in_outline

Zozaya, L. 2014. "Cursos online de Paleografía: herencias, limitaciones, logros y propuestas”. El profesional de la información 23 (5): 475-484. Acesso em 09 jan 2020. https://doi.org/10.3145/epi.2014.sep.04 
Para citar este texto:

Marcotulio, Leonardo Lennertz e Vanessa Martins do Monte. 2021. "Algumas notas sobre o ensino de Paleografia no Brasil". Investigación Bibliotecológica: archivonomía, bibliotecología e información 35 (87): 57-84.

http://dx.doi.org/10.22201/iibi.24488321xe.2021.87.58291 